\title{
Congenital quadricuspid aortic valve anomaly associated with hypertrophic non-obstructive cardiomyopathy: a case report and review of the literature
}

\author{
Uwe Janssens, Heinrich G Klues, Peter Hanrath
}

\begin{abstract}
A case is reported of a 38 year old woman without known cardiac congenital abnormality but a history of well controlled arterial hypertension who was admitted to hospital after successful resuscitation at home following cardiac arrest. There was no evidence of myocardial infarction on 12-lead electrocardiogram but there were signs of left ventricular hypertrophy. Transoesophageal echocardiography revealed a rare quadricuspid aortic valve (QAV) malformation with concomitant mild aortic regurgitation. The left ventricle showed a massive concentric hypertrophy without obstruction. The patient was eventually transferred in a persistent vegetative state to a home care facility. A review of the literature revealed 70 cases of QAV diagnosed by transthoracic or transoesophageal echocardiography (26 cases), at necropsy (25), during surgery (15), and during angiography (4). The present case is the first report of QAV associated with non-obstructive hypertrophic cardiomyopathy.
\end{abstract}

(Heart 1997;78:83-87)

Keywords: heart defects; congenital anomaly; echocardiography; cardiomyopathy; aortic valve abnormalities

Congenital abnormalities affecting the quadricuspid aortic valve (QAV) are very rare, far less common than unicuspid or bicuspid valve congenital abnormalities which have received considerable attention in recent years. ${ }^{1}$ Most cases of QAV have been discovered as an incidental finding at necropsy, during aortic valve replacement or aortic angiography. ${ }^{2-4}$ Cross sectional transthoracic or transoesophageal echocardiography are the preferred methods to detect this malformation. ${ }^{25-16}$

Medical Clinic I, University of Aachen, Aachen, Germany

U Janssens

H G Klues

$P$ Hanrath

Correspondence to:

Dr.med. U Janssens, Medical

Clinic I, University of

Aachen, Pauwelsstraße 30,

D-52057 Aachen, Germany.

Accepted for publication

29 January 1997
A 38 year old woman $(155 \mathrm{~cm}, 80 \mathrm{~kg})$ with a 10 year history of arterial hypertension well controlled with $\beta$ blockers and clonidine suffered sudden syncope, apnoea and documented bradycardia followed by cardiac arrest. She was successfully resuscitated at home after a latency period of 10 minutes. On admission the patient was deeply comatose. She was mechanically ventilated but intravenous analgesics and sedatives were not administered. The patient had a sinus tachycardia ( 120 beats/min) and blood pressure was $200 / 120 \mathrm{~mm} \mathrm{Hg}$. A 12-lead electrocardiogram showed no signs of acute myocardial infarction, however, there were signs of left ventricular hypertrophy-a positive Sokolow-Lyon index ( $S$ in V1 and $R$ in V5 $4.4 \mathrm{mV}$ ) and negative $T$ waves in leads V4-V6. There was no significant elevation of aspartate aminotransferase, lactic dehydrogenase, or creatinine kinase on admission or during later serial measurements. Cardiac output measured by thermodilution was within the normal range $(5.6 \mathrm{l} / \mathrm{min})$ as were pulmonary artery wedge pressure $(10 \mathrm{~mm} \mathrm{Hg})$ and pulmonary-systemic vascular resistance (72 dyn.sec. $\mathrm{cm}^{-5} / 1296$ dyn.sec. $\mathrm{cm}^{-5}$ ). Cranial computed tomography excluded cerebral haemorrhage, masses, and cerebral oedema. Fundoscopic examination showed grade 1 vascular changes according to the Keith-Wagener classification. Transthoracic and transoesophageal cross sectional echocardiography revealed massive concentric hypertrophy (figure) of a nondilated left ventricle without regional wall motion abnormalities. There was no systolic anterior motion (SAM) of the mitral valve. Septal thickness was $24 \mathrm{~mm}$ and free wall thickness $18 \mathrm{~mm}$ (septal to free wall ratio 1·3:1). Continuous wave and pulsed Doppler ultrasound excluded flow acceleration within the left ventricular outflow tract. Short axis view of the aortic valve demonstrated four thin cusps all of equal size with an " $x$-shaped" commissural pattern of the closed valve and normal full excursion of the leaflets to the margins of the aortic annulus (figure). The accessory cusp was situated between the right and left coronary cusp, the left coronary ostium was located in the middle of the left coronary cusp, and the right coronary ostium in the middle of the right coronary cusp. There was only mild central aortic insufficiency detected by colour flow mapping resulting from incomplete diastolic coaptation of the cusps.

Clinical course was determined by the development of a persistent vegetative state owing to the delayed resuscitation. The 
Magnification of the transoesophageal short axis view of the aortic valve during diastole $(A)$ and systole $(B)$ demonstrating four equally sized aortic valve cusps. Transgastric short axis view $(C)$ and slightly modified transoesophageal two chamber view (D) of a patient with hypertrophic non-obstructive cardiomyopathy and a septal thickness of $24 \mathrm{~mm}$.
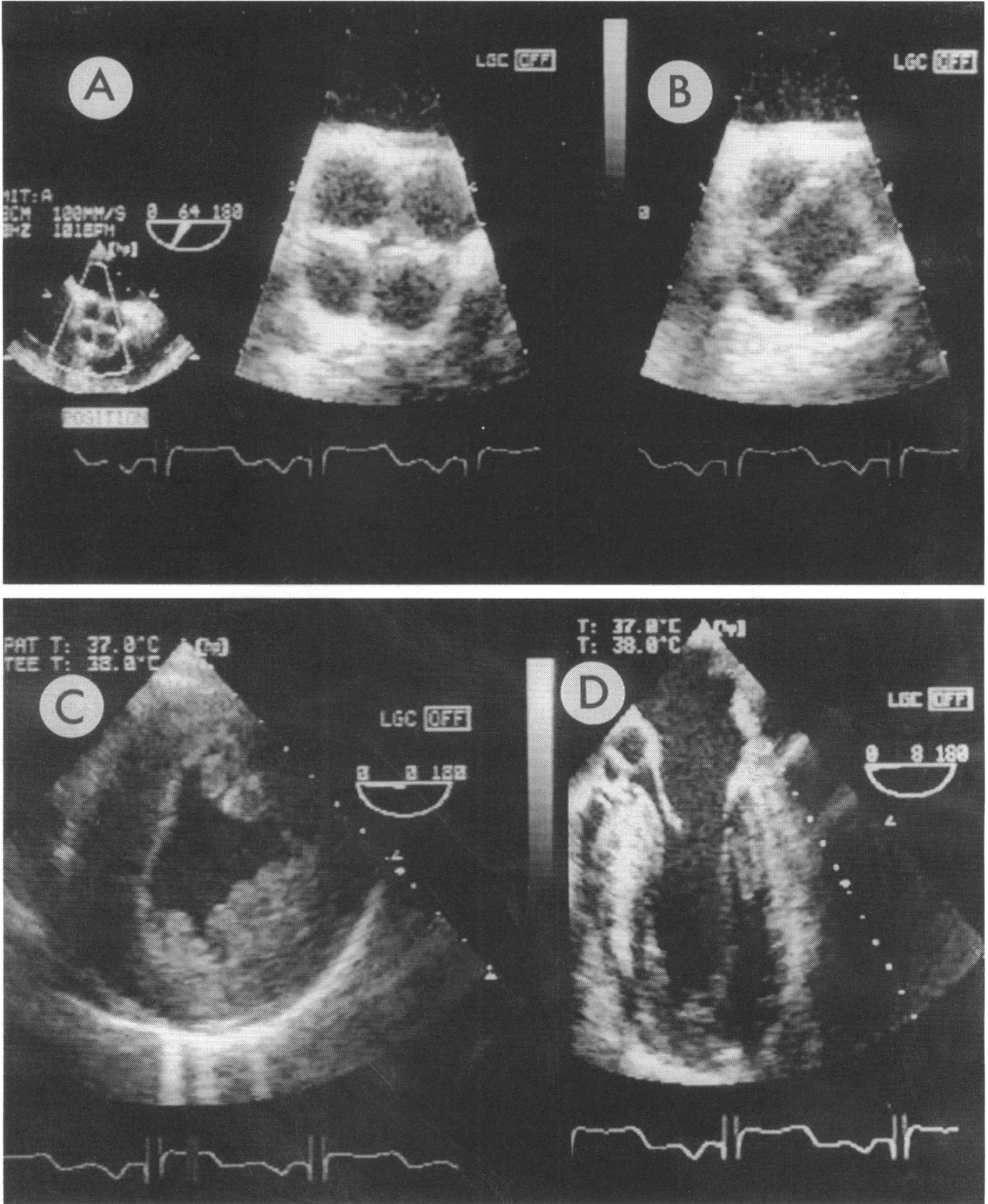

patient was transferred to a home care facility.

There was no history of hypertrophic cardiomyopathy or sudden cardiac death in the patient's family. Her father and one brother died from complications associated with myocardial infarction. A sister with two sons had no echocardiographic abnormalities.

\section{Discussion}

Normally, after septation of the embryological arterial trunk, three mesenchymal swellings develop into semilunar leaflets of the aortic and pulmonary trunk. However, in the setting of a QAV, the entire formation of the aortic root must deviate from normal with formation of sinuses, leaflets, and interleaflet triangles. The mechanism involved in this formation is not fully understood. ${ }^{8}$ This congenital malformation has to be distinguished from pseudoquadricuspid aortic valves that results from bacterial endocarditis and other pathological processes such as rheumatic valve disease eroding through a cusp, thus leading to the appearance of a QAV. Pathologists and clinicians pay attention to semilunar valves with an abnormal number of cusps, especially bicuspid ( $2 \%$ of the general population $)^{17}$ and unicuspid valves because these malformations are frequently stenotic or incompetent and may require surgical treatment. Quadricuspid semilunar valves seem to be far less common and are reported to occur nine times more frequently in pulmonic valves than aortic valves. ${ }^{18}$

In 1923 Simonds reported five cases of native QAVs in 25666 necropsies collected from the world literature-an incidence of $0.003 \% .{ }^{19}$ In another series of 6000 necropsies, two QAVs were found $(0 \cdot 008 \%) .{ }^{1}$ A retrospective analysis of 60446 echocardiograms revealed eight QAVs $(0.013 \%) .^{6}$ found 70 QAVs (table). Most of these were diagnosed most recently by transthoracic
Our review of the international literature 
Quadricuspid aortic valve: review of the literature

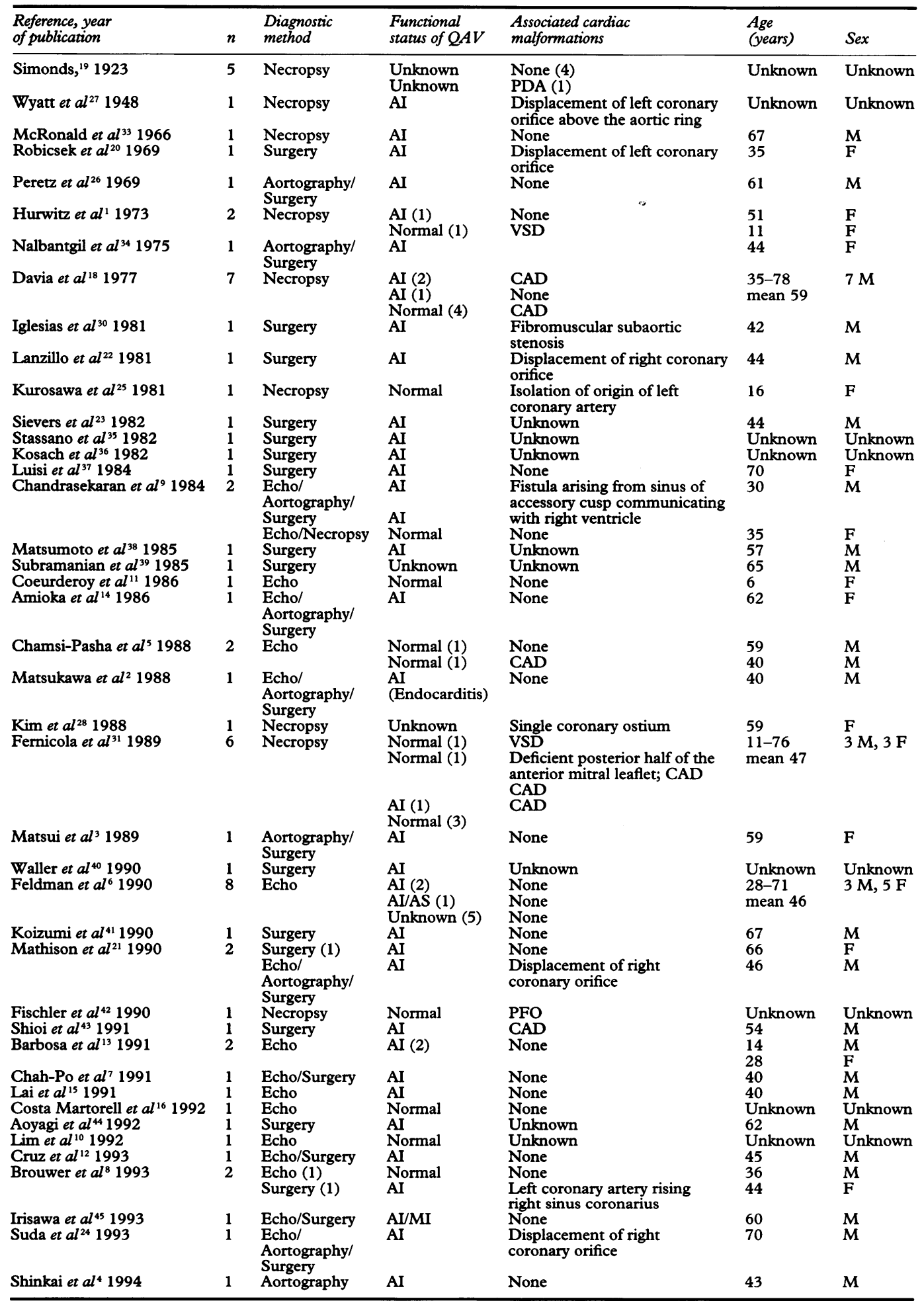

$\mathrm{AI}$, aortic insufficiency; AS, aortic stenosis; CAD, coronary artery disease; F, female; $M$, male; PDA, patent ductus arteriosus; PFO, patent foramen ovale; QAV, quadricuspid aortic valve; VSD, ventricle septum defect.

or transoesophageal echocardiography (26 cases), followed by necropsy (25), surgery (15), and angiography (4).

The mean age when QAV was first diagnosed was 49 years (range 6-78). Thirty six $(62 \%)$ of the patients were male and $28(38 \%)$ were female. Hurwitz and Roberts also found quadricuspid pulmonic valves to be more common in men.

A recent report described different anatomical variations according to the size of the indi- vidual aortic valve cusps: four unequal cusps, three equal cusps and one smaller cusp, and up to four equal cusps. ${ }^{1}$ The cusps in our patient were all of equal size representing the less common distribution. In this case the accessory cusp was located between the right and left cusp. Transoesophageal echocardiography allowed imaging of the proximal portions of the left and right coronary artery. There was no displacement or obstruction of the right or left coronary ostium by accessory 
cusp tissue as has been reported in some patients with QAV proved at surgery or necropsy. ${ }^{80-24}$ One sudden cardiac death occurred in a 16 year old boy with QAV and complete isolation of the orifice of the left coronary artery by an adherent aortic valve cusp..$^{25}$

Aortic regurgitation appears to be the most prevalent haemodynamic abnormality associated with QAV and occurred in 39 of 70 $(56 \%)$ cases, whereas valvular stenosis was very rare. In 26 of the cases, aortic valve replacement was necessary because of severe valve incompetence. Only $18 \mathrm{QAVs}$ had a normal functional status without significant regurgitation or stenosis. Aortic regurgitation seems to be more common in patients with an additional smaller cusp leading to unequal distribution of stress and abnormal leaflet coaptation that possibly results in progression of aortic regurgitation. ${ }^{6}$ Therefore, these patients may require prophylaxis against subacute bacterial endocarditis, although in general the equally sized QAVs have no increased risk for infection. Infective fenestration of a valve cusp or fibrous valve thickening may also result in incomplete coaptation of the cusps thus leading to regurgitation. ${ }^{26}$

There are only a few reports concerning the association of QAV with other cardiac defects. Of these, anomalies of the coronary ostium and coronary arteries are the most frequent. ${ }^{6820-22} 252728$ Apart from ventricular septal defects, patent ductus arteriosus, subaortic fibromuscular stenosis, and a malformation of the mitral valve can be associated with a QAV. ${ }^{19}$ 29-31

To the best of our knowledge this is the first report of a QAV associated with non-obstructive hypertrophic cardiomyopathy. The patient had a history of arterial hypertension, used elsewhere as an exclusion criterion when making the diagnosis of idiopathic hypertrophic cardiomyopathy. Duration of hypertension was only 10 years and well controlled with $\beta$ blockers and clonidine according to her family and her physician. These facts and the results of fundoscopy (grade 1) showed that there was no accelerated malignant form of hypertension. Our echocardiographic findings of massive left ventricular hypertrophy with asymmetric septal hypertrophy (septal to free wall ratio 1·3:1) cannot be explained solely by the patient's mild hypertension and has therefore to be regarded as a genuine disorder of the heart in terms of hypertrophic nonobstructive cardiomyopathy.

Karam et al investigated 39 patients with hypertrophic cardiomyopathy and hypertension and compared them with age and sex matched patients with cardiomyopathy alone. Their results indicate that hypertrophic cardiomyopathy with associated hypertension might be a disease of the elderly. The echocardiographic features of the patients with hypertension were indistinguishable from those with cardiomyopathy without hypertension. These findings suggest that hypertension may make hypertrophy worse, but that it is not the primary cause of the cardiomyopathy. Thus this condition should be better termed "hypertrophic cardiomyopathy with hypertension". ${ }^{32}$

This case report and the review of the literature demonstrate that the QAV is a very rare, congenital anomaly of the aortic valve with an incidence between $0.003 \%$ and $0.013 \%$. It may be found incidentally in an asymptomatic patient but is most often found in patients with aortic regurgitation. In the past, QAV was recognised at surgery or necropsy but now transthoracic and transoesophageal echocardiography play a pivotal role in diagnosing this rare valve malformation. Cross sectional echocardiography, colour flow Doppler and particularly the transoesophageal approach can easily assess the morphological and functional status of such a valve.

1 Hurwitz LE, Roberts WC. Quadricuspid semilunar valve. Am $\mathcal{F}$ Cardiol 1973;31:623-6.

Matsukawa T, Yoshii S, Hashimoto R, Muto S, Suzuki S Ueno A. Quadricuspid aortic valve perforation resultin from bacterial endocarditis-2-D echo- and angiographic diagnosis and its surgical treatment. $f_{p n}$ Circ $\mathcal{f}^{1988}$ 52:437-40.

3 Matsui K, Kohno H, Kurisu K, Murakami S, Fukuyama T Quadricuspid aortic valve-report of a case associated with severe aortic regurgitation and review of the literawith severe aortic regurgitation

4 ture. fpn f Surg 1989;19:93-7. $H$, Nasu $M$, Sono J, Okada Y, et al. An operative case of aortic regurgitation due to quadricuspid valve. Kyobu Geka 1994;47:311-14. Chamsi-Pasha H, Barnes PC, Beton DC. EchocardioChamsi-Pasha H, Barnes PC, Beton DC. Echocardio-
graphic diagnosis of quadricuspid aortic valve. Eur Heart $\mathcal{f}$ 1988;9:1269-70.

6 Feldman BJ, Khanderia BK, Warnes CA, Seward JB Taylor CL, Tajik AJ. Incidence, description and functional assessment of isolated quadricuspid aortic valves Am $\mathcal{F}$ Cardiol 1990;65:937-8.

7 Chah-Po L, Koyanagi S, Sadoshima J, Takeshita A. Transesophageal echocardiographic findings of quadricuspid

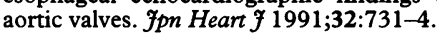

8 Brouwer MHJ, de Graaf J, Ebels T. Congenital quadricuspid aortic valve. Int $\mathcal{F}$ Cardiol 1993;38:196-8.

9 Chandrasekaran K, Tajik AJ, Edwards WD, Seward JB Two-dimensional echocardiographic diagnosis of quadricuspid aortic valve. Am $\mathcal{\text { Cardiol }}$ 1984;53:1732-3.

10 Lim YT, Choo MH, Ling LH. Echocardiographic diagnosis of quadricuspid aortic valve. Ann Acad Med Singapore 1992;21:841-2.

11 Coeurderoy A, Biron Y, Laurent M, Almange C. Congenital quadricuspid aortic valve. Apropos of a case Review of the literature. Arch Mal Coeur Vaiss 1986;79: 745-8.

12 Cruz LA, Castier MB, Ferro ME, Menezes CC, Albanesi Filho FM. Aortic insufficiency due to quadricuspid aortic valve. Arq Bras Cardiol 1993;60:103-5.

13 Barbosa MM, Motta MS. Quadricuspid aortic valve and aortic regurgitation diagnosed by Doppler echocardiography: report of two cases and review of the literature. $\exists \mathrm{Am}$ Soc Echocardiogr 1991;4:69-74.

14 Amioka $H$, Okamoto $M$, Matsumoto $K$, Yamagata $T$, Yokote Y, Sakura E, et al. Echo and Doppler cardiographic findings of isolated quadricuspid aortic valve: a case report and a review of the literature. $f$ Cardiogr 1986;16:1003-11.

15 Lai CP, Koyanagi S, Sadoshima J, Takeshita A, Tokunaga $\mathrm{K}$. Transesophageal echocardiographic findings of quadricuspid aortic valve. Ipn Heart $\mathcal{F}_{1991 ; 32: 731-4}$.

16 Costa Martorell J, Rivas Puy I, Peraire JJ, Bardaji A, Ridao C, Richart C. Quadricuspid aortic valve. Presentation of new case and review of the literature. Rev Esp Cardiol

17 Roberts WC. The congenitally bicuspid aortic valve. A study of 85 autopsy cases. Am $\mathcal{F}$ Cardiol 1970;26:72-83.

18 Davia JE, Fenoglio J, DeCastro CM, McAllister HA Cheitlin MD. Quadricuspid semilunar valves. Chest 1977;72:186-9.

19 Simonds JP. Congenital malformations of the aortic and pulmonary valves. Am $\mathcal{F}$ Med Sci 1923;166:584-95.

20 Robicsek F, Sanger PW, Daugherty HK, Montgomery CC. Congenital quadricuspid aortic valve with displacement of the left coronary orifrice. Am $f$ Cardiol 1969;23 288-90.

21 Mathison M, Furuse A, Kotsuda H, Tanaka O, Chikada M. Quadricuspid aortic valve: case reports. Kyobu Geka 1990;43:383-8.

22 Lanzillo G, Breccia PA, Intonti F. Congenital quadricuspid aortic valve with displacement of the right coronary or fice. Scand 7 Thorac Cardiovasc Surg 1981;15:149-51.

23 Sievers HH, Regensburger D, Bernhard A. Quadricuspid aortic valve with significant insufficiency. Thorac aortic valve with significa

24 Suda H, Rikitake K, Furukawa K, Shiraishi R, Kurashige Y, Mori E, Itoh T. Quadricuspid aortic valve: a case 
report and the review of the literature. Kyobu Geka 1993; 46:283-6.

25 Kurosawa $\mathrm{H}$, Wagenaar SS, Becker AE. Sudden death in a youth. A case of quadricuspid aortic valve with isolation of origin of left coronary artery. Br Heart $f$ 1981;46: 211-15.

26 Peretz DI, Changfoot GH, Gourlay RH. Four-cusped aortic valve with significant hemodynamic abnormality. $A m \mathcal{F}$ Cardiol 1969;23:291-3.

27 Wyatt JP, Goldenberg H. Supernumeracy aortic cusps with multiple fenestrations and with displacement of the left coronary orifice. Arch Pathol 1948;45:784.

28 Kim H-S, McBride RA, Titus JL. Quadricuspid aortic valve and single coronary ostium. Arch Pathol Lab Med 1988;112:842-4.

29 Feizi ÖF, Farrer-Brown G, Emanuel R. Familial study of hypertrophic cardiomyopathy and congenital aortic valve disease. Am $₹$ Cardiol 1978;41:956-64.

30 Iglesias A, Oliver J, Munoz JE, Nunez L. Quadricuspid aortic valve associated with fibromuscular subaortic stenosis and aortic regurgitation treated by conservative surgery. Chest 1981;80:327-8.

31 Fernicola DJ, Mann JM, Roberts WC. Congenitally quadricuspid aortic valve: analysis of six necropsy patients. Am f Cardiol 1989;63:136-8.

32 Karam R, Lever HM, Healey BP. Hypertensive hypertrophic cardiomyopathy or hypertrophic cardiomyopathy with hypertension? A study of 78 patients. $\mathcal{F} \mathrm{Am}$ Coll Cardiol 1989;13:580-4.

33 McRonald RE, Dean DC. Congenital quadricuspid aortic valve. Am F Cardiol 1966;18:761-3.

34 Nalbantgil I, Cagatay G. Quadricuspid aortic valve [letter] Chest $1975 ; 67: 623-4$.
35 Stassano P, Iorio D, Di Lello F, Tecchia LB, Spampinato $\mathrm{N}$. Aortic insufficiency due to quadricuspid valve. Minerva Cardioangiol 1982;30:7-9.

36 Kosach GA, Evzhanov A, Serbin VI, Zubkova GA Tadzhibaeva ZA. Quadricuspid aortic valve. Kardiologiia 1982;22:113-14

37 Luisi VS, Pasque A, Verunelli F, Aliboni M, Urbano U, Reginato E. Quadricuspid aortic valve. $\mathcal{F}$ Cardiovasc Surg Torino 1984;25:252-4

38 Matsumoto M, Miki S, Kusuhara K, Ueda Y, Ohkita Y, Tahata T, Komeda M. Quadricuspid aortic valve associated with severe aortic regurgitation. Fpn Circ F 1985;49:190-1.

39 Subramanian R, Olson LJ, Edwards WD. Surgical pathology of combined aortic stenosis and insufficiency: a study of 213 cases. Mayo Clin Proc 1985;60:247-54.

40 Waller BF, Taliercio CP, Dickos DK, Howard J, Adlam $\mathrm{JH}$, Jolly W. Rare or unusual causes of chronic, isolated, pure aortic regurgitation. Clin Cardiol 1990;13:577-81.

41 Koizumi S, Arai S, Kato T. A case of quadricuspid aortic valve with aortic regurgitation. Kyobu Geka 1990;43: valve wi 8 .

42 Fischler D, Fitzmaurice M, Ratliff NB. Quadricuspid aortic valve. Am f Cardiovasc Pathol 1990;3:91-4.

43 Shioi K, Nagata Y, Kato S, Kato R, Tsuchioka H. A case of quadricuspid aortic valve associated with coronary arterial egion. Nippon Kyobu Geka Gakkai Zasshi 1991;39: 1072-6.

44 Aoyagi S, Kawara T, Yasunaga H, Kosuga K, Oishi K. Congenital quadricuspid aortic valve associated with aortic regurgitation. Thorac Cardiovasc Surg 1992;40:225-6.

45 Irisawa T, Yoshiya K, Yokosawa T, Iwamatsu T, Arai K Aoki T. A case of quadricuspid aortic valve associated with mitral regurgitation. Kyobu Geka 1993;46:618-21.

\section{IMAGES IN CARDIOLOGY}

\section{Non-invasive detection of quadricuspid aortic valve}

Transthoracic echocardiography of a 66 year old Japanese woman with a history of cardiac murmur from early childhood showed large regurgitant blood flow from the aortic valve into the left ventricle that continued until the end of the diastolic phase.

Cine magnetic resonance imaging (MRI) revealed unexpected results: the aortic valve was quadricuspid (normal sized right cusp, slightly smaller left cusp, and half sized two non-coronary cusps without enlargement of annulus). The images of the end diastolic phase (left panel) and the mid-systolic phase

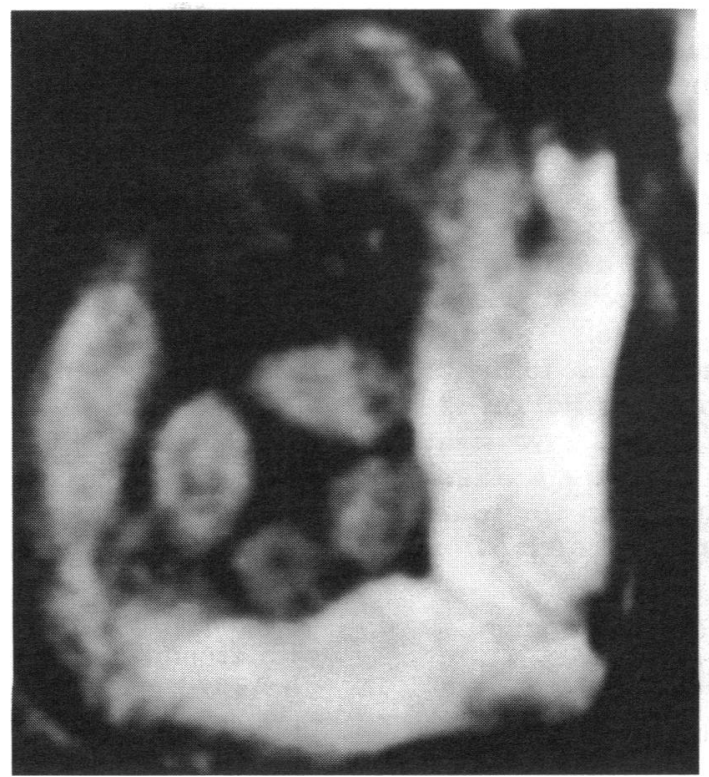

(right panel) showed that these four cusps could not close completely even at the end of the diastolic phase resulting in the formation of a "regurgitant window" (approximately $8 \times 8 \mathrm{~mm}$ ). MRI also showed that her pulmonary valve was tricuspid. This non-invasive examination clearly demonstrated both the presence of a quadricuspid aortic valve and the relation between structure and function of this rare aortic valve anomaly.

KOUII KAJINAMI NOBORU TAKEKOSHI HIROSHI MABUCHI

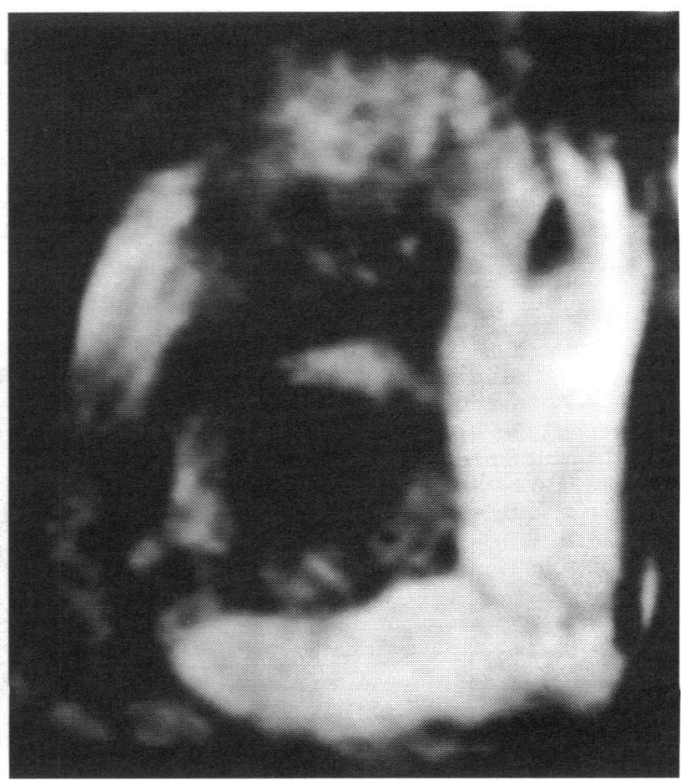

